\title{
AS METAS DO PLANO NACIONAL DE EDUCAÇÃO (2014-2024) PARA A EDUCAÇÃO BÁSICA: um estudo preliminar da região dos cerrados do centro-norte do Brasil
}

\author{
Sandra Fernandes Leite 6 \\ Sueli Helena de Camargo Palmen
}

\section{RESUMO}

Esse artigo apresenta um mapeamento do PNE - Plano Nacional de Educação (Lei $n^{\circ}$ 13.005/ 2014) sobre as metas: 01, 02, 03, 08, 09, 10, 11, 12 e 15, ou seja, relacionadas à Educação Básica e focando especificamente no Centro-Norte do Brasil, uma região que recobre parcialmente os estados do Maranhão (Sul), Tocantins (Leste), Piaú (Sul) e Bahia (Oeste) e onde estão surgindo novos polos de expansão da agricultura brasileira. O objetivo desse trabalho foi levantar um conjunto de metas do PNE para a região dos cerrados do Centro-Norte do Brasil para estabelecer um quadro do andamento do PNE na região e estabelecer uma abordagem preliminar de relação entre a educação e o desenvolvimento da região. Foi realizada uma pesquisa bibliográfica e documental pautada nos dados do Plano Nacional de Educação focalizando as metas relacionadas à Educação Básica. Como recorte de estudo, em cada sub-região dos cerrados do CentroNorte do Brasil foram selecionados seis municípios para levantamento dos indicadores educacionais, sendo três municípios que apresentam impacto das atividades do agronegócio na economia local e que se constituem em centralidade urbana e com economia agropecuária no contexto regional e três municípios que, embora dentro da região de influência do agronegócio, tiveram pouco ou nenhum impacto nas dinâmicas econômicas municipais. Esta pesquisa assume que essas metas do PNE ao estabelecerem as diretrizes, as metas e as estratégias para a educação nacional, possuem impacto direto no projeto de desenvolvimento regional e na melhoria da qualidade de vida da população do Centro-Norte do Brasil.

Palavras-chave: Plano Nacional de Educação. Educação Básica. Indicadores Educacionais.

\footnotetext{
6 Doutora em Educação. Docente da Faculdade de Educação da Universidade Estadual de Campinas/UNICAMP. Integrante do grupo de Pesquisa GEPALE da FE/UNICAMP. E-mail: sfleite@unicamp.br

7 Doutora em Educação pela Faculdade de Educação/UNICAMP. Docente de Educação Infantil da Rede Municipal de Educação de Campinas - SP. E-mail: suelipalmen@gmail.com
} 


\title{
BRAZILIAN NATIONAL EDUCATION PLAN - PNE (2014-2024) GOALS FOR BASIC EDUCATION: a preliminary study on the brazilian center-north region
}

\begin{abstract}
This article presents the goals 01 02,03,08,09, 10, 11, 12 and 15 in Brazilian PNE Brazilian National Education Plan on Brazilian Center-North region. These goals are related to Basic Education. The Brazilian Center-North is a region that partially covers the states of Maranhão (South), Tocantins (East), Piauí (South) and Bahia (West) and where new expansion poles of Brazilian agriculture are emerging. The aim of this study was to gather a set of PNE goals for the Brazilian Center-North region to establish the PNE's progress in the region and to define a preliminary approach to the relationship between education and the development in the region. A bibliographical and documentary research was carried out based on the data of the Brazilian National Plan of Education (PNE) focusing on the goals listed above. In each sub-region of the Brazilian Center-North region we selected six municipalities to survey the educational indicators, three municipalities that have an impact on agribusiness activities in the local economy and that constitute an urban centrality with an agricultural and livestock economy in the regional context. Three municipalities that, although within the region of agribusiness influence, had little or no impact on the municipal economic dynamics. This article assumes that these PNE goals have a direct impact on the regional development project and the improvement of the life quality of its population, establishing the guidelines, goals and strategies for national education throughout the Brazilian Center-North region.
\end{abstract}

Keywords: Brazilian National Education Plan. Basic Education. Educational Indicators.

\section{INTRODUÇÃO}

Os cerrados do Centro-Norte do Brasil são uma região que recobre parcialmente os estados do Maranhão, Tocantins, Piauí e Bahia e onde surgem novos polos de expansão da agricultura modernizada brasileira (ALVES, 2015) (GARAGORRY et. al., 2015). O potencial de desenvolvimento agropecuário dessa região influencia diretamente no desenvolvimento econômico sustentável fundado nas atividades agrícolas e pecuárias que consequentemente oportuniza condições para que se pense em ações potencializadoras de políticas públicas voltadas para a melhoria de vida da população dessa região.

Os cerrados do Centro-Norte do Brasil são uma região em formação que ganha destaque e emergência de dinâmicas econômicas associadas 
ao agronegócio e suas distintas formas de manifestações, tais como: a mobilidade de população, formas específicas de produção e de urbanização, construção de infraestrutura para a aceleração dos fluxos de informações e de mercadorias. Esse fenômeno é gerador na região de graves implicações ambientais e no modo de vida das comunidades rurais, variadas formas de uso da terra e da água, concentração da estrutura fundiária, disputa pelo território, dentre tantas outras situações (ALVES, 2015). Junto a essas transformações também está uma demanda crescente por capacitação e ampliação da educação nessa região. A melhoria da educação encontra diversos desafios frente às demandas exigidas por essa área de expansão da agropecuária tecnificada e em expansão.

Ao analisar O Plano Nacional de Educação (BRASIL, 2014) selecionamos algumas metas relacionadas à Educação Básica para o mapeamento inicial das condições educacionais da região pesquisada, pontuando os indicadores específicos dentro de cada meta. Este trabalho assumiu que essas metas elencadas possuem impacto direto no projeto de desenvolvimento econômico e na melhoria da qualidade de vida local:

- Meta 01 - a Educação Infantil, o indicador foi o percentual de crianças que frequentam a Educação Infantil de 0 a 3 anos (creche) e de 4 a 5 anos (Pré-escola);

- Meta 2 - o Ensino Fundamental, o indicador foi o percentual da população de 6 a 14 anos no ensino fundamental (nove anos);

- Meta 3 - o Ensino Médio, o indicador foi o percentual da população de 15 a 17 anos nesta etapa da educação básica (Meta 3);

- Meta 8 - o indicador do percentual da população de 18 a 29 anos com o mínimo de 12 anos de estudo no último ano de vigência do PNE;

- Meta 9 - o indicador da elevação da taxa de alfabetização da população com 15 anos ou mais até 2015 e o fim do analfabetismo até o final deste PNE (Meta 9);

- Meta 10 - a modalidade Educação de Jovens e Adultos - EJA, percentual de matrículas na EJA (integrada ao ensino profissional);

- Meta 11 - a Educação Profissional Técnica de nível médio, percentual de matrículas no ensino médio profissionalizante;

- Meta 12 - o Ensino Superior, o indicador foi o percentual de matrícula no ensino superior olhando para as oportunidades dos egressos do ensino médio; e

- Meta 15 - Formação de Professor de Educação Básica no Ensino Superior, percentual de professores da Educação Básica com formação no ensino superior.

(BRASIL, 2014). 
Com base no trabalho desenvolvido por Alves (2015) para a região do Centro-Norte do Brasil, foram selecionados alguns municípios que possuem características em comum para servirem de base na verificação dos impactos das metas do PNE. Considerando nosso universo amostral, buscamos mapear os municípios considerando seu tamanho populacional e as características de renda da administração pública (PIB municipal e IDH, por exemplo) e de seus moradores (Renda per capta). A região recobre parcialmente os estados do Maranhão, Tocantins, Piauí e Bahia e dentro de cada mesorregião desses estados, destacamos que a seleção dos municípios utilizou os critérios associados ao agronegócio:

- Municípios que apresentam impacto na economia local gerado pelo agronegócio;

- Municípios que embora estejam dentro da região de influência do agronegócio, possuem pouco ou nenhum impacto em suas dinâmicas socioeconômicas.

Especificamos no Quadro 1 e na Figura 1 os municípios de abrangência da região de estudo que norteiam a coleta dos dados que compõem essa pesquisa:

Quadro 1: Municípios de abrangência da região de estudo do Centro-Norte do Brasil.

\begin{tabular}{|c|c|}
\hline SUB-REGIÃO & MUNICÍPIOS \\
\hline $\begin{array}{l}\text { Oeste da Bahia } \\
\text { Mesorregião Extremo Oeste } \\
\text { Baiano }\end{array}$ & $\begin{array}{l}\text { Barreiras, Luís Eduardo Magalhães, São } \\
\text { Desiderio, Riachão das Neves, Santa Rita de } \\
\text { Cássia e Formosa do Rio Preto }\end{array}$ \\
\hline $\begin{array}{l}\text { Leste do Tocantins } \\
\text { Mesorregião Oriental do } \\
\text { Tocantins }\end{array}$ & $\begin{array}{l}\text { Dianópolis, Campos Lindos, Pedro Afonso, Porto } \\
\text { Nacional, Almas e Santa Rosa do Tocantins }\end{array}$ \\
\hline $\begin{array}{l}\text { Sul do Piauí } \\
\text { Mesorregião Sudoeste Piauiense }\end{array}$ & $\begin{array}{l}\text { Uruçuí, Bom Jesus, Santa Filomena, Monte } \\
\text { Alegre do Piauí, Redenção do Gurguéia e } \\
\text { Corrente }\end{array}$ \\
\hline $\begin{array}{l}\text { Sul do Maranhão } \\
\text { Mesorregião Sul Maranhense }\end{array}$ & $\begin{array}{l}\text { Balsas, Alto Parnaíba, Benedito Leite, São } \\
\text { Raimundo das Mangabeiras, Carolina e Porto } \\
\text { Franco }\end{array}$ \\
\hline
\end{tabular}


Figura 1: Localização dos municípios selecionados nos cerrados do Centro-Norte do Brasil8.

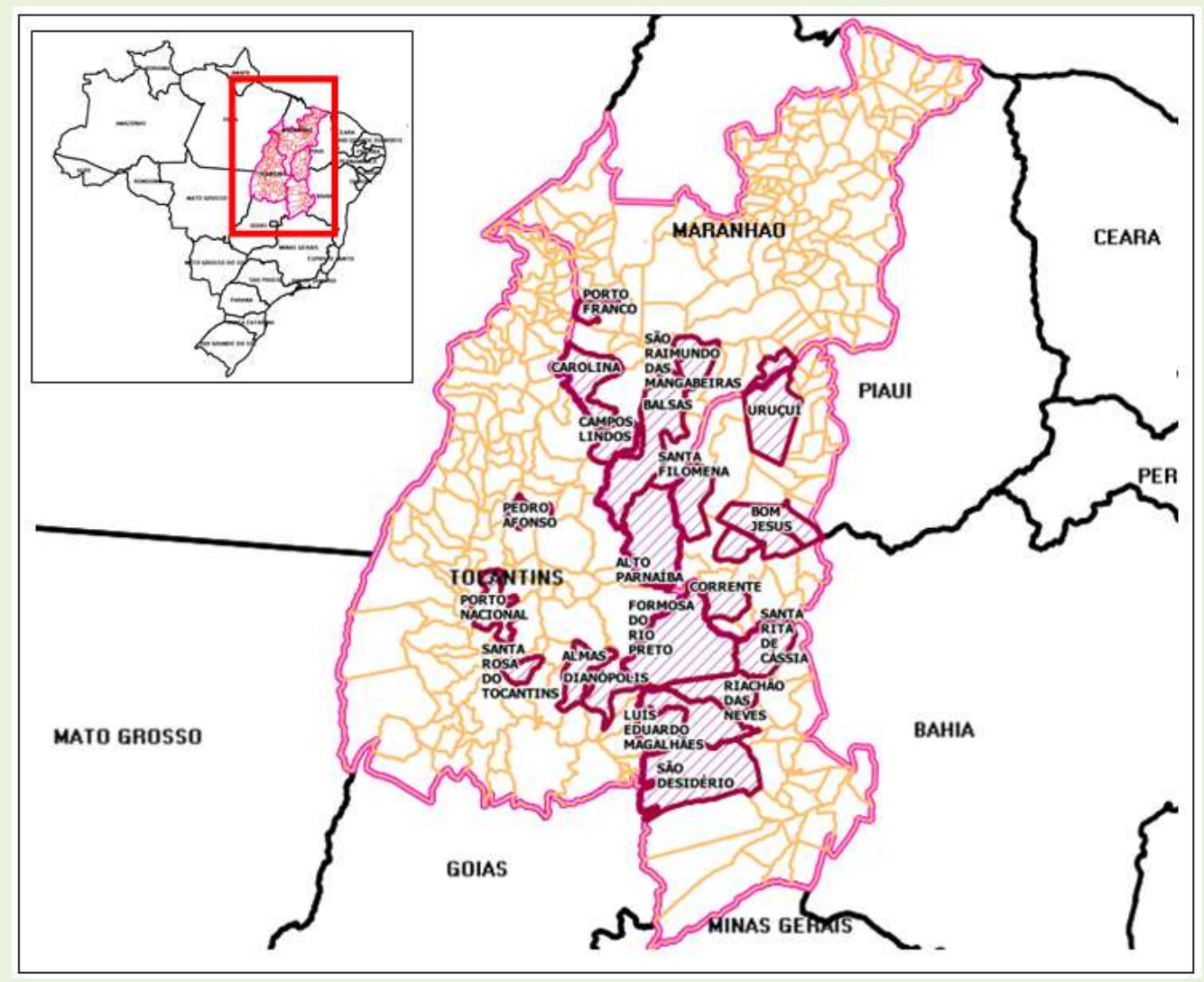

Nesse sentido, buscou-se compreender se os indicadores educacionais, vinculados a metas selecionadas para análise, estabelecem relação com essa dinâmica econômica introduzida pelo agronegócio e suas diferenciações socioeconômicas e espaciais produzidas no contexto regional.

\footnotetext{
8 A região dos Cerrados do Centro-Norte do Brasil também é denominada por outros autores como MATOPIBA (MIRANDA et. al., 2015), sendo o termo e a região formalmente definida pelo Decreto 8.447, de 6 de maio de 2015 (BRASIL, 2015). Para fins desse estudo, usaremos o termo Centro-Norte do Brasil.
} 


\section{OS CERRADOS DO CENTRO-NORTE DO BRASIL NA RECENTE CONSTITUIÇÃO REGIONAL DO AGRONEGÓCIO}

A região dos cerrados do Centro-Norte do Brasil se insere na área do Bioma Cerrados 9 e de terrenos sedimentares que formam os platôs planos, por onde avançam os cultivos mecanizados em larga escala de grãos.

As condições naturais propícias ao avanço da agricultura mecanizada e os incentivos governamentais (incentivos fiscais, créditos subsidiados em bancos públicos, política de transferência de terras públicas para grupos econômicos privados etc.) favoreceram sobremaneira, ainda na década de 1970, a instalação dos primeiros grupos econômicos, predominantemente migrantes de origem do Sul do Brasil e empresas de diversos ramos econômicos em busca de aquisição de terras baratas para produção e especulação imobiliária (ALVES, 2006). Foram estes grupos os responsáveis por impulsionarem a nova economia. A partir de então, observa-se um intenso crescimento dos cultivos especialmente de soja, cultura agrícola que se tornou predominante na região.

No novo contexto de modernização agropecuária, a região atraiu capital e força de trabalho. Com o crescimento da produção modernizada no campo, a região passou a estabelecer maior articulação com outros espaços nacionais e mundiais, na medida em que ali se realiza uma produção agropecuária voltada para o grande mercado consumidor, especialmente o mercado externo. Na agricultura, a ênfase ao longo dos anos foi dada para a produção de grãos. A pecuária também se destaca nesses espaços com a criação de gado bovino a partir do uso de técnicas avançadas, o que possibilitou nos últimos anos a modernização desse setor (ALVES, 2006).

Segundo Alves (2015), o espaço urbano de algumas cidades dessa região, da mesma maneira, teve uma trajetória de mudanças importantes, passando de lugares com poucas alterações na sua dinâmica econômica e 9 IBGE. Território e Biomas Continentais Brasileiros. Disponível em: http://brasilemsintese.ibge.gov.br/ territorio.html. Acesso em 30/11/2016. 
espacial para cidades de grande dinamismo. É nesse contexto que algumas cidades se transformaram substancialmente aportando crescimento expressivo de sua economia e expansão da sua área de abrangência do urbano, que resulta da intensa migração de população que foi expulsa do campo ou de moradores deslocados de outras regiões. Particularmente essa dinâmica possui relação muito próxima com o avanço da agricultura modernizada e, por conta disso, foram denominadas de "cidades do agronegócio" (ELIAS, 2011; FREDERICO, 2011).

Essas cidades se destacam pela forte presença de atividades voltadas para agricultura modernizada e que sobrevivem basicamente dos resultados produtivos alcançados por esse setor, embora a economia mercantil oriunda da pequena agricultura familiar continue existindo e tendo força na escala regional. Na nova realidade econômica regional, sobressai um conjunto de cidades que se destaca como áreas de especialização produtiva, na medida em que passam a possuir centralidade para 0 atendimento de serviços voltados para as atividades produtivas do campo: lojas de maquinários, de sementes e de defensivos; escritórios de prestação de serviços agropecuários etc. Mas também expandiu velozmente nessas áreas o consumo de outras mercadorias destinadas à população, tanto de bens de consumo não duráveis quanto duráveis.

A dinâmica produtiva, entretanto, não se espalha com a mesma intensidade para todos os municípios da região. Pelo contrário, a maior parte deles, mesmo ocorrendo aumento da modernização agrícola no campo, isso não significou dinamização da economia urbana. Tal fato criou, nesse sentido, municípios cujas áreas urbanas ganharam centralidade econômica e outros cujas cidades continuaram apresentando economias com fraco desempenho no que diz respeito à sua articulação na rede urbana regional (ALVES, 2015).

Com base em Alves (2006) e Alves (2015) foi possível estabelecer uma classificação hierárquica da rede urbana regional dos cerrados do CentroNorte do Brasil a partir dos municípios escolhidos para essa pesquisa, 
considerando os municípios que adquiriram centralidade econômica com a instalação das atividades do agronegócio e aqueles que continuam com uma economia urbana basicamente vinculada ao atendimento da população local.

\section{UM LEVANTAMENTO PRELIMINAR DA EDUCAÇÃo NOS CERRADOS DO CENTRO-NORTE DO BRASIL}

O Ministério da Educação (MEC) disponibiliza diversas estatísticas e indicadores, como o Índice de Desenvolvimento da Educação Básica - IDEB, que possibilitam o monitoramento da qualidade da Educação pela população (BRASIL, 2015). Uma importante fonte para mapeamento, acompanhamento e análise das metas educacionais é o próprio documento do Plano Nacional de Educação Lei n. ${ }^{\circ}$ 13.005/2014, que com seus indicadores nos permitem desenhar a situação educacional de forma particularizada, pesquisando cada município da região estudada em profundidade e considerando o cenário local.

Apesar dos Órgãos Oficiais do Governo disponibilizarem diversas estatísticas, indicadores e dados sobre os estados e municípios, ainda não se tem um quadro específico sistematizado para essa região dos cerrados do Centro-Norte do Brasil e nem uma visão da educação sobre um recorte dessa região.

Em um levantamento preliminar com base no IDEB dos municípios pudemos constatar que os cerrados do Centro-Norte são uma região que apresenta uma série de contrastes educacionais. Com base no IDEB - Índice de Desenvolvimento da Educação Básica de 2013 (INEP, 2015a), com foco para o Ensino Fundamental Anos Iniciais, os cerrados do Centro-Norte do Brasil possuem alguns municípios com IDEBs elevados até para a média nacional, como o município de Combinado no estado do Tocantins, com 6,2 (LEITE, 2016). Observando os Estados, nos Anos Finais do Ensino Fundamental e no Ensino Médio, todos os quatro Estados que compõem os cerrados do 
Centro-Norte estão abaixo da média nacional. Apenas para os anos iniciais do Ensino Fundamental o Tocantins supera a média brasileira de $2013 \mathrm{com}$ IDEB de 5,0 (INEP, 2015b).

\section{ANÁLISE PRELIMINAR DAS 9 METAS NOS 24 MUNICÍPIOS SELECIONADOS}

Considerando os 24 municípios escolhidos nas mesorregiões dos cerrados do Centro-Norte do Brasil, realizamos um mapeando preliminar das metas 01 , 02, 03, 08, 09, 10, 11, 12 e 15 do PNE. Utilizamos como fonte de pesquisa o portal oficial do Ministério da Educação - Portal do PNE10, através do qual realizamos o levantamento de cada meta num tempo inicial que antecede a vigência do atual PNE, a fim de construirmos parâmetros para percebermos os avanços educacionais em cada um desses municípios/regiões ao longo da implementação do PNE. Os índices foram escolhidos de forma a revelar desafios a serem enfrentados como: estruturas físicas específicas encontradas em cada localidade, recursos humanos com ou sem a qualificação desejada, rede de apoio no alcance das metas estabelecidas.

Analisando em detalhes cada uma das metas escolhidas foi possível perceber a situação de tais municípios em termos educacionais e quais são os desafios a serem enfrentados para o atendimento das metas em suas especificidades. Considerando que a Meta 1 do PNE refere-se a universalização da Educação Infantil - Pré Escola até 2016, ou seja, garantir que todas as crianças de 4 e 5 anos estejam matriculadas na Educação Infantil, retomando a região estudada temos o Piauí como o Estado que mais tem efetivado a ampliação desse atendimento apresentando um percentual de $93,9 \%$ das matrículas, enquanto o Tocantins está entre os quatro estados que compõem a região do Cerrados do Centro-Norte do Brasil com o menor percentual, comparativamente $(67,4 \%)$.

10 Portal do PNE. Disponível em: http://pne.mec.gov.br/monitorando-e-avaliando. Acesso em: 04/12/2016. 
Figura 2: Meta 1 - Educação Infantil.

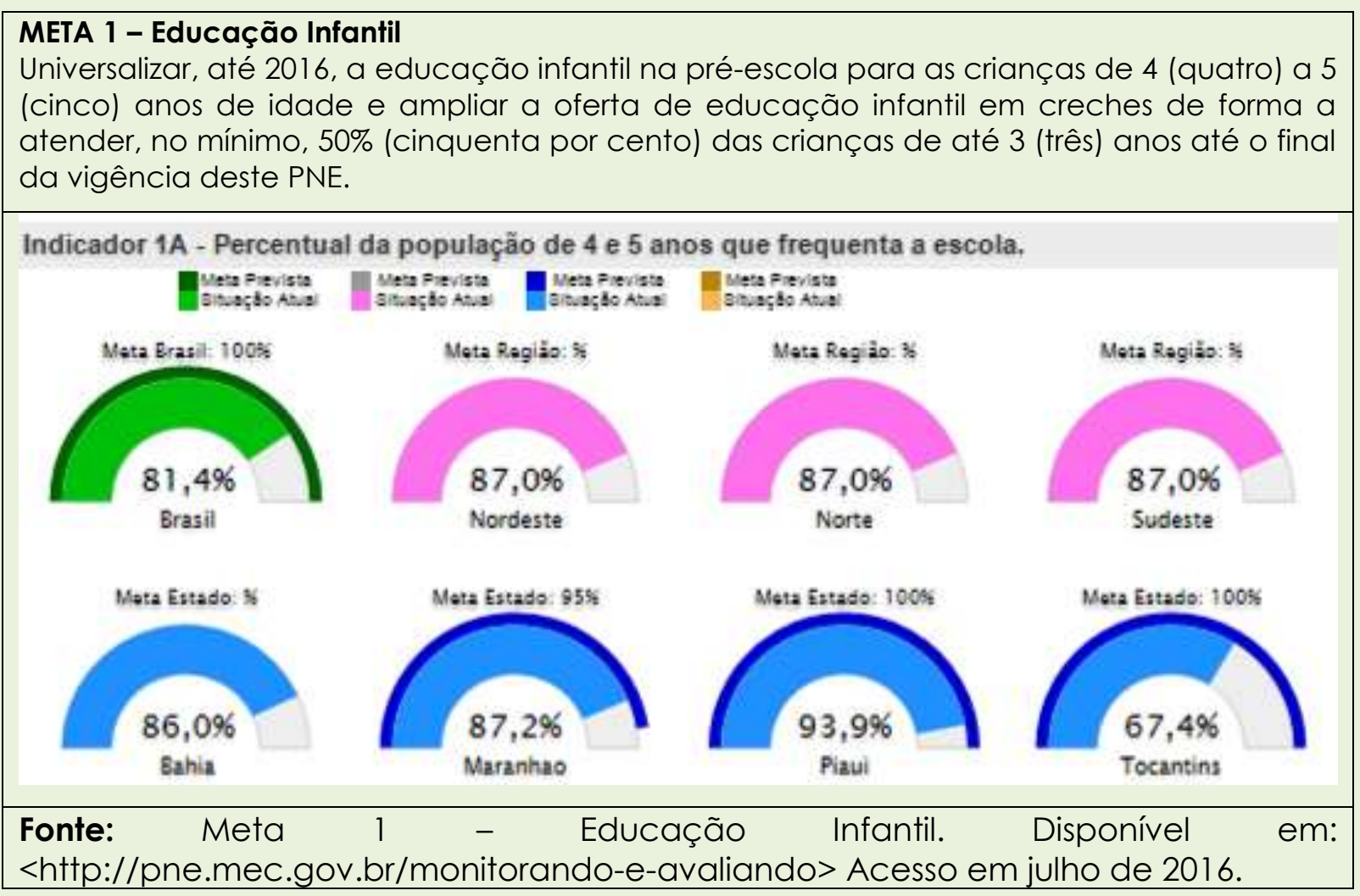

Essa informação é importante porque pode nos dar pistas para verificar se é somente a nova economia que proporciona maior acesso educacional ou é a participação do Estado nesse processo que leva a universalização educacional.

Focando os municípios que compõem a região dos cerrados do Centro-Norte do Brasil e que estão envolvidos nesta pesquisa vemos que Redenção do Gurguéia (PI) é o que mais se aproxima da universalização da Educação Infantil - Pré escola, apresentando o índice de $95,9 \%$ dos atendimentos, enquanto que no Estado do Tocantins o município que mais se distancia da meta estabelecida é Santa Rosa do Tocantins com $43,6 \%$ das matrículas de crianças entre 4 e 5 anos, como vemos nos indicadores a seguir na figura 3. 
Figura 3: Meta 1 - Educação Infantil nos municípios escolhidos no Piauí e no Tocantins.

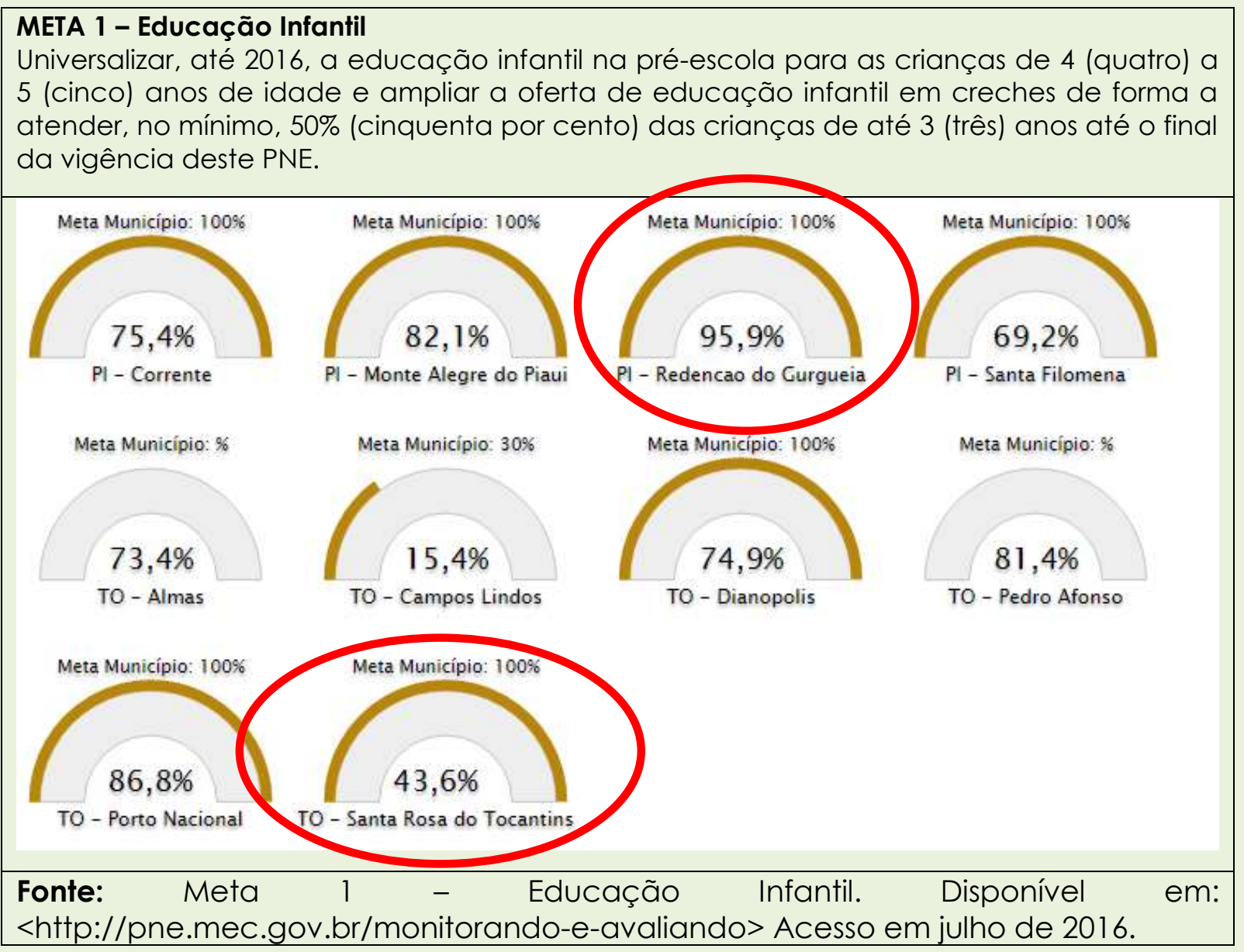

Considerando que Redenção do Gurguéia (95,9\%) não sofre a influência do agronegógio (ALVES, 2015), temos um elemento de discussão sobre a relação de influência do desenvolvimento agropecuário e o acesso à educação, visto que Santa Rosa do Tocantins apresentou elevado crescimento na economia agropecuária com a expansão dos campos de soja e apresenta um indicador de 43,6.

Ao enfocar a universalização do Ensino Fundamental (Meta 2) de 9 anos para toda a população de 6 a 14 anos e garantir que pelo menos $95 \%$ dos alunos concluam essa etapa na idade recomendada, até o último ano de vigência do PNE, atualmente nos encontramos nacionalmente com o atendimento desse público em $98,4 \%$, mas quando o foco é o percentual de pessoas com 16 anos que concluem o ensino fundamental, o índice nacional 
em 2013 era de 66,7\%, distante da meta que é de $95 \%$ até o final da vigência do PNE.

Voltando o olhar para os municípios desta proposta de pesquisa, o atendimento do público com a idade entre 6 a 14 anos, apenas o município de Campos Lindos - TO apresenta o menor índice de atendimento (92,8\%).

Na tabela 2 podemos acompanhar como cada município envolto nesse mapeamento preliminar tem apresentado seus indicadores educacionais, dentro das metas 2, 3, 8, 9, 12 e 15 do Plano Nacional de Educação, sendo que as metas abaixo de $50 \%$ estão destacadas em vermelho:

Tabela 2: Indicadores das Metas Educacionais nos municípios selecionados para a pesquisa.

\begin{tabular}{|c|c|c|c|c|c|c|}
\hline MUNICíPIO & $\begin{array}{c}\text { META 2 - } \\
\text { ENS. FUND. }{ }^{11} \\
\text { INDICADOR } \\
12\end{array}$ & $\begin{array}{c}\text { META 3 - } \\
\text { ENSINO. } \\
\text { MÉDIO }^{13}\end{array}$ & META 814 & META 915 & $\begin{array}{c}\text { META } \\
\mathbf{1 2}^{16}\end{array}$ & $\begin{array}{c}\text { META } \\
\mathbf{1 5}^{17}\end{array}$ \\
\hline Oeste da Bahia & & & & & & \\
\hline Barreiras & 97,5 & 79,9 & $\mathbf{4 4 , 6}$ & 89,7 & $\mathbf{2 7 , 3}$ & $\mathbf{3 3 , 7}$ \\
\hline $\begin{array}{c}\text { Luís Eduardo } \\
\text { Magalhães }\end{array}$ & 96,4 & 76,1 & 57,0 & 92,8 & $\mathbf{1 4 , 7}$ & $\mathbf{4 0 , 7}$ \\
\hline São Desiderio & 95,8 & 80,2 & 76,1 & 74,5 & $\mathbf{9 , 0}$ & $\mathbf{1 7 , 2}$ \\
\hline Riachão das Neves & 95,0 & 83,1 & 70,9 & 69,8 & $\mathbf{1 0 , 0}$ & $\mathbf{5 , 6}$ \\
\hline Santa Rita de Cássia & 97,5 & 84,7 & 64,4 & 78,9 & $\mathbf{6 , 1}$ & $\mathbf{1 5 , 5}$ \\
\hline Formosa do Rio Preto & 97,3 & 86,3 & 63,7 & 77,7 & $\mathbf{9 , 4}$ & $\mathbf{2 9 , 4}$ \\
\hline Leste do Tocantins & & & & & & \\
\hline Dianópolis & 97,5 & 88,6 & 51,7 & 87,6 & $\mathbf{1 3 , 3}$ & 56,7 \\
\hline Campos Lindos & 92,8 & 70,6 & 75,7 & 79,0 & $\mathbf{4 , 1}$ & $\mathbf{2 8 , 6}$ \\
\hline Pedro Afonso & 97,4 & 83,8 & $\mathbf{4 7 , 5}$ & 89,6 & $\mathbf{1 6 , 9}$ & 54,6 \\
\hline Porto nacional & 98,3 & 87,2 & $\mathbf{4 1 , 3}$ & 90,8 & $\mathbf{4 0 , 0}$ & 51,6 \\
\hline Almas & 94,4 & 72,2 & 62,6 & 78,3 & $\mathbf{7 , 7}$ & $\mathbf{4 3 , 5}$ \\
\hline $\begin{array}{c}\text { Santa Rosa do } \\
\text { Tocantins }\end{array}$ & 97,0 & 90,9 & 65,4 & 82,3 & $\mathbf{1 0 , 3}$ & $\mathbf{3 9 , 8}$ \\
\hline Sul do Piauí & & & & & & \\
\hline Uruçuí & 97,0 & 85,8 & 63,4 & 81,9 & $\mathbf{1 7 , 3}$ & $\mathbf{2 6 , 9}$ \\
\hline
\end{tabular}

11 Universalizar o ensino fundamental de 9 (nove) anos para toda a população de 6 (seis) a 14 (quatorze) anos e garantir que pelo menos 95\% (noventa e cinco por cento) dos alunos concluam essa etapa na idade recomendada, até o último ano de vigência deste PND.

12 Percentual da população de 6 a 14 anos que frequenta a escola.

13 Universalizar, até 2016, o atendimento escolar para toda a população de 15 (quinze) a 17 (dezessete) anos e elevar, até o final do período de vigência deste PNE, a taxa líquida de matrícula do ensino médio para $85 \%$ (oitenta e cinco por cento).

14 Percentual da População de 18 a 29 anos com menos de 12 anos de escolaridade.

15 Taxa de alfabetização da população com 15 anos ou mais.

16 Percentual de matrícula no ensino superior.

17 Percentual de professores da Educação Básica com formação no ensino superior. 


\begin{tabular}{|c|c|c|c|c|c|c|}
\hline Bom Jesus & 97,9 & 78,2 & 58,3 & 81,6 & $\mathbf{3 1 , 2}$ & $\mathbf{4 8 , 3}$ \\
\hline Santa Filomena & 97,6 & 84,3 & 80,9 & 75,3 & $\mathbf{4 , 9}$ & $\mathbf{2 7 , 3}$ \\
\hline Monte Alegre do Piauí & 98,3 & 85,2 & 71,2 & 76,3 & $\mathbf{2 2 , 1}$ & $\mathbf{1 4 , 5}$ \\
\hline $\begin{array}{c}\text { Redenção do } \\
\text { Gurguéia }\end{array}$ & 97,9 & 82,9 & 66,8 & 78,2 & $\mathbf{1 4 , 1}$ & $\mathbf{4 2 , 4}$ \\
\hline Corrente & 97,3 & 89,8 & 62,4 & 81,2 & $\mathbf{3 2 , 1}$ & $\mathbf{2 8 , 0}$ \\
\hline Sul do Maranhão & & & & & & \\
\hline Balsas & 94,4 & 78,5 & 57,9 & 87,1 & $\mathbf{1 6 , 9}$ & $\mathbf{2 6 , 7}$ \\
\hline Alto Parnaíba & 95,1 & 83,3 & 73,6 & 78,8 & $\mathbf{1 1 , 4}$ & $\mathbf{9 , 0}$ \\
\hline Benedito Leite & 97,6 & 84,0 & 75,3 & 70,8 & $\mathbf{1 1 , 7}$ & $\mathbf{3 1 , 2}$ \\
\hline $\begin{array}{c}\text { São R. das } \\
\text { Mangabeiras }\end{array}$ & 98,2 & 87,3 & 69,4 & 79,7 & $\mathbf{4 , 5}$ & $\mathbf{2 5 , 6}$ \\
\hline Carolina & 95,1 & 81,8 & 69,0 & 84,9 & $\mathbf{1 0 , 6}$ & $\mathbf{2 6 , 7}$ \\
\hline Porto Franco & 97,7 & 80,5 & 57,5 & 84,6 & $\mathbf{1 8 , 1}$ & $\mathbf{4 0 , 0}$ \\
\hline
\end{tabular}

Fonte para onsino fundamental. Disponível em: http://simec.mec.gov.br/pde/graficopne.php (dados de 2013) /Fonte para o ensino médio: $\mathrm{http} / / /$ pne.mec.gov.br/monitorando-e-avaliando/ Fonte para as metas 12 e 15: Estado, Região e Brasil - IBGE - Pesquisa Nacional por Amostra de Domicílios (PNAD), 2013/Município e Mesorregião - IBGE - Censo Demográfico - 2010.

Contudo, quando o foco é o percentual de pessoas que concluem o ensino fundamental aos 16 anos, o município com a melhor situação é Porto Nacional (TO), apresentando o índice de $68,9 \%$ de pessoas que concluem essa etapa do ensino com 16 anos, superando o índice nacional, que segundo os gráficos do PNE em movimento 18, em 2013 era de $66,7 \%$.

O município de Santa Filomena (PI) é que tem o maior desafio nessa meta, pois apenas $28 \%$ da população que está no ensino fundamental concluem essa etapa do ensino na idade esperada, 16 anos.

Direcionando o mapeamento para o Ensino Médio - Meta 3, cujo objetivo é a universalização do ensino médio para a população de 15 a 17 anos (prevista para 2016), o índice nacional era de $84,3 \%$, conforme os dados do IBGE/ PNAD - 2013 (IBGE, 2014).

Segundo os dados do IBGE/ PNAD - 2013, quando olhamos para Campos Lindos (TO) temos um índice de 70,6\%, portanto abaixo do percentual nacional, enquanto que Santa Rosa do Tocantins apresentava em 2013 o percentual de $90,9 \%$ de atendimento, compreendendo o público de 15 a 17 anos, superando o indicador nacional.

18 PNE em Movimento. Disponível em: http://simec.mec.gov.br/pde/graficopne.php. Acesso em 10/07/2016. 
Outra meta elencada pelo PNE refere-se a elevação da escolaridade (Meta 8). A referida meta busca elevar a escolaridade média da população de 18 a 29 anos, de modo a alcançar, no mínimo, 12 anos de estudo no último ano de vigência deste Plano, principalmente para as populações do campo, da região de menor escolaridade no País e dos $25 \%$ mais pobres, além de apontar outra meta dentro da meta que é de igualar a escolaridade média entre negros e não negros, diferença declarada pelo Instituto Brasileiro de Geografia e Estatística - IBGE (IBGE, 2014).

Entre os municípios que compõem nossa amostragem e que tem a população com idade entre 18 e 29 anos com menos de 12 anos de escolaridade temos na seguinte ordem: Santa Filomena (PI) com 80,9\%, São Desidério (BA) com 76,1\%, Campos Lindos (TO) com 75,7\% e Benedito Leite (MA) com 75,3\%.

A escolaridade média da população de 18 a 29 anos de idade nos estados que compõem a região dos Cerrados do Centro-Norte não chega a média nacional, que é de 9,8 anos de escolaridade. Observa-se ainda que, apesar da maioria dos municípios da região estarem com índices, em sua maioria, bem superiores a 50\%, os municípios de Barreiras (BA), Pedro Afonso (TO) e Porto nacional (TO) estão na casa dos $40 \%$. Barreiras é um exemplo de município com grande influência do agronegócio.

A meta 9, referente a Alfabetização de jovens e adultos, tem como objetivo a elevação da taxa de alfabetização da população com 15 anos ou mais para $93,5 \%$ até 2015 e erradicação do analfabetismo até o final deste PNE.

Nos estados envolvidos vemos que o Tocantins é o que apresenta 0 maior índice de alfabetização, 87,8\% da população com idade de 15 anos ou mais, seguido da Bahia com $85,1 \%$, Piauí, $80,3 \%$ e Maranhão, $80,2 \%$, índices distantes da meta, como preconiza o presente PNE.

Luis Eduardo Magalhães (BA) apresenta a taxa de alfabetização da população de 15 anos ou mais de $92,8 \%$, enquanto em Riachão das Neves (BA) apresenta o menor indice referente a essa meta (69,9\%) quando 
comparada com os demais municípios participantes da amostragem montada para essa proposta de pesquisa. Ou seja, o Estado da Bahia é o que apresenta um indice acima da média nacional, mas também o menor indice de alcance da meta 9 quando focamos a amostragem da região dos cerrados do Centro-Norte do Brasil.

A Educação de Jovens e Adultos - EJA integrada a educação profissional, com um mínimo de $25 \%$ das matrículas da educação de jovens e adultos, nos ensinos fundamental e médio integrada ao ensino profissional - meta 10, ainda é um desafio nacional, pois no Brasil apenas 2,8\% das matrículas da EJA acontecem dessa forma.

Nos estados de Maranhão, Tocantins, Piauí e Bahia, especificamente nos municípios selecionados para o mapeamento preliminar, Piaui é o estado que apresenta o maior índice de integração da educação de jovens e adultos ao ensino profissionalizante $(9,2 \%)$ e o Maranhão o menor índice de integração $(2,6 \%)$, sendo que a Bahia possui $4,0 \%$ e o Tocantins, $3,7 \%$.

Destacamos abaixo os municípios que apresentam em cada um dos estados relacionados o maior índice de integração da EJA ao ensino profissionalizante:

- Redenção do Gurgueia (PI) com 37,7\%;

- Santa Rita de Cássia (BA) com 22,4\%;

- Dianópolis (TO) com 17,8\% e,

- São Raimundo das Mangabeiras (MA) com 14,3\%.

A Meta 11 - Educação Profissional prevê triplicar as matrículas da educação profissional técnica de nível médio, assegurando a qualidade da oferta e pelo menos $50 \%$ da expansão no segmento público.

Nos municípios focados, as matrículas no ensino profissional público se destacam na Bahia, especificamente em Barreiras com 2.148 matrículas, segundo dados do Censo da Educação Básica de 2013 e 2014.

Vários municípios participantes desta pesquisa não apresentam matrículas no ensino profissional, o que indica que falta uma política de expansão desse seguimento educacional na região, fato que torna-se uma 
deficiência para o avanço de uma economia do agronegócio, que por sua vez demanda de mão-de-obra qualificada e esbarra numa deficiência local em termos de formação profissional especializada.

Quando o foco é o ensino superior, temos a meta 12 especificando como objetivo a necessidade de elevar o número de matrículas no ensino superior para $50 \%$ e nesse sentido vemos que o Tocantins é o estado que apresenta o maior indice de matrícula, contudo ainda distante na meta estabelecida para a ampliação, conforme mostra a figura 3.

Figura 4: Meta 2 - Educação Superior nos Estados do Centro-Norte do Brasil.

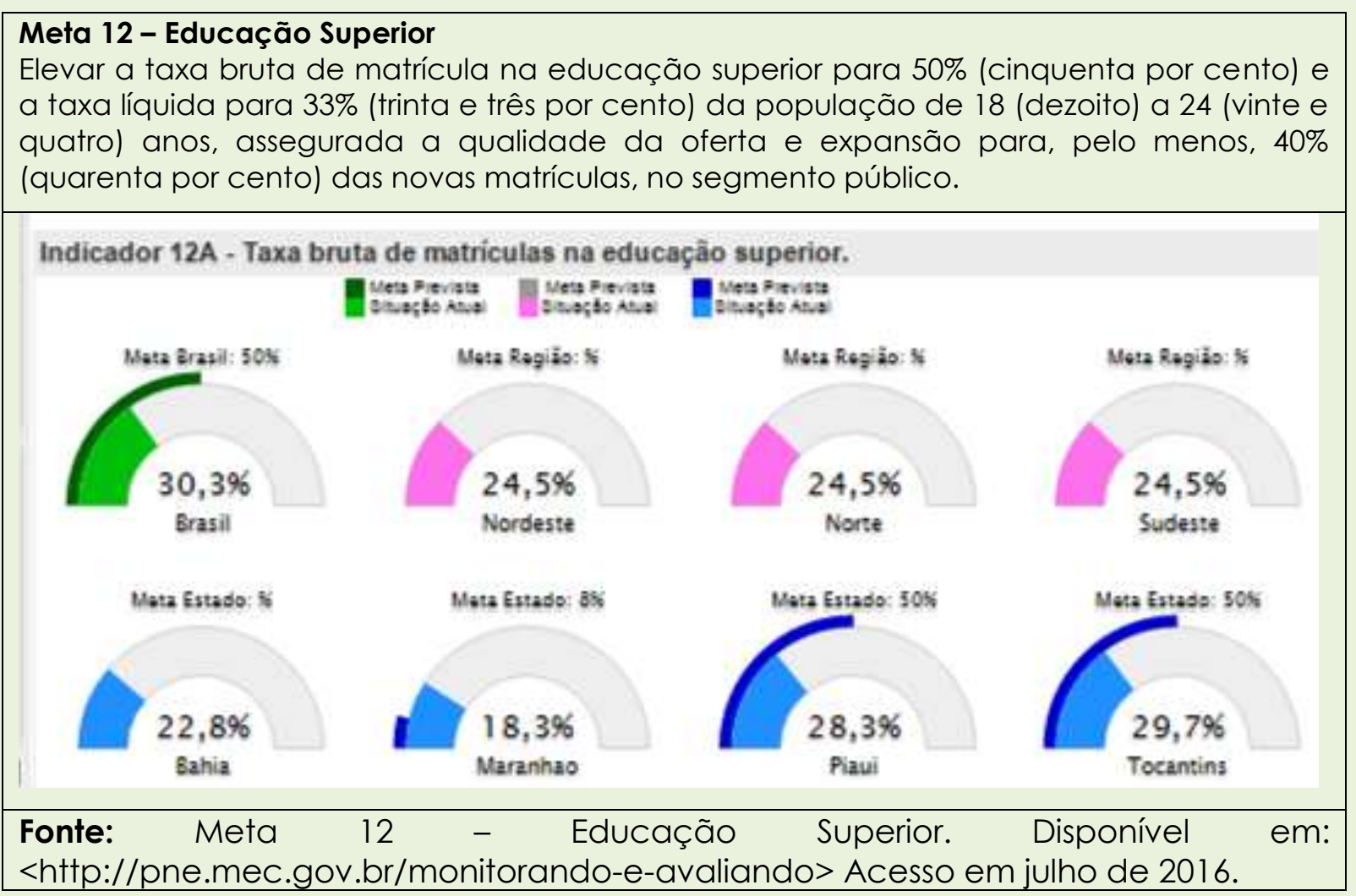

Analisando os dados, vemos que a meta 12 está próxima ao seu alcance no município de Porto Nacional (TO), com o índice de $40 \%$ das matrículas brutas no ensino superior (matrículas no setor público e privado). Esse índice mais elevado de acesso ao ensino superior pode ter relação com a presença de uma universidade federal e de outras instituições de ensino 
superior privado no município. Ainda assim, essa meta em todos os municípios selecionadas é inferior a $50 \%$.

O município de Campos Lindos (TO) é o que apresenta menor indice de matrículas no ensino superior $(4,1)$ revelando diferentes realidades dentro do mesmo estado. Essa situação é similar nos demais estados: Bahia, Maranhão e Piaú, o que indica a ocorrência de desigualdades municipais e sua influência na execução de cada uma das metas do PNE.

Por fim, na Meta 15 do PNE o foco são os Profissionais de Educação. Assim, o regime de colaboração entre a União, os Estados, o Distrito Federal e os Municípios são estabelecidos como uma meta visando a formação dos profissionais da educação, conforme preconiza a Lei $n^{\circ}$ 9.394, de 20 de dezembro de 1996 (LDB, artigo 61), assegurando que todos os professores da educação básica possuam formação específica de nível superior, obtida em curso de licenciatura na área de conhecimento em que atuam.

Sobre o índice de profissionais da educação básica com formação superior, o estado de Tocantins conta com 49,3\%, o estado de Piaú com $38,9 \%$, o estado da Bahia com $28,9 \%$ e o estado do Maranhão com 25,2\%.

Focalizando a meta 15 nos municípios envolvidos nesse mapeamento verifica-se que em Dianópolis (TO) é onde podemos notar a maior presença de docentes com Ensino Superior (56,7\%). Já o menor índice de professores formados no ensino superior é encontrado em Riachão das Neves (BA), com apenas $5,6 \%$ do quadro docente com a qualificação no ensino superior.

No Estado do Piauí os índices de professores com qualificação em nível superior para a educação infantil não superam os $50 \%$ e no ensino fundamental chega a $64,5 \%$ de docentes com formação superior. É no Estado do Tocantins que encontramos os indicadores mais altos, considerando que ultrapassa os $60 \%$ para os professores que atuam na educação infantil e chegando a mais de $80 \%$ para os docentes do ensino fundamental (LEITE, 2016).

Uma grave distorção observada na região é o número de docentes com curso de licenciatura, mas que não atuam na área de formação e 
sendo mínimo o número de docentes com licenciatura que atuam em suas áreas de formação (LEITE, 2016). O acesso a pós-graduação também é preocupante, considerando que nos cursos de especialização os índices vão pouco além dos $20 \%$. O acesso aos cursos de mestrado e de doutorado é praticamente inexistente (LEITE, 2016).

\section{CONSIDERAÇÕES FINAIS}

O atual Plano Nacional de Educação - Lei n 13.005/2014 estará em vigor até 2024. Trata-se de um plano aprovado com força constitucional e que, portanto, ultrapassa governos. Diante do cenário atual do País de grande instabilidade política e econômica e com uma dívida histórica com a educação brasileira, marcada pela exclusão, pelo fracasso escolar e tantas outras mazelas que exigem do país, compromissos com a educação que não podem mais ser adiados. Entre eles os desafios de universalizar a oferta da etapa obrigatória da Educação Básica para crianças e jovens de 04 a 17 anos, elevar o nível de escolaridade da população, melhorar a qualidade da Educação Básica e Superior e ampliar o acesso ao Ensino Técnico e Superior.

O PNE propõe que o Distrito Federal, cada estado e cada munícipio tenham seus respectivos planos estaduais e municipais de educação, elaborados em consonância com o Plano Nacional. Em um primeiro olhar para os estados e municípios que esse artigo destaca, observou-se que os estados da Bahia, Tocantins, Piauí e Maranhão já elaboraram os Planos Estaduais de Educação.

Um ponto nodal desse Plano trata-se da necessidade de avaliação periódica do próprio PNE. Avaliar o que será efetivamente garantido ao final da década, revendo metas e estratégias ao longo da década é essencial na efetivação deste. Constata-se que sendo o Brasil um país de extensão continental e realidades diversas, o monitoramento e avaliação do atual PNE - Lei n 13.005/2014 é de suma relevância para o país. 
Olhando para a região que compõem os cerrados do Centro-Norte do Brasil e considerando a diversidade e os desafios não só de dar conta de compreender a realidade educacional, tem-se o desafio e, ao mesmo tempo, o compromisso de garantir a efetivação do debate e da avaliação do que vem ocorrendo na implementação do atual PNE (2014-2024), uma vez que o plano é nacional, mas se efetiva de fato nos municípios.

Esse artigo buscou estabelecer as primeiras relações entre 0 desenvolvimento experimentado por essa região do Centro-Norte do Brasil e as metas associadas à Educação Básica no PNE (2014-2024). Em linhas gerais, observa-se um bom desempenho nas metas 2, 3 e 9 (associadas ao Ensino Fundamental, Ensino Médio e Alfabetização para 15 anos ou mais) para os 24 municípios, variando entre valores de $92,8 \%$ a $98,3 \%$ para a meta 2 , de $70,6 \%$ a $90,9 \%$ para a meta 3 e de $69,8 \%$ a $92,8 \%$ para a meta 9 . Os desafios se mostram para as metas 12 e 15, associadas ao ensino superior e à formação de professores. Nessas metas, a totalidade dos municípios na meta 12 está abaixo de 50\% e praticamente todos os municípios na meta 15.

\section{REFERÊNCIAS}

ALVES, V.E.L. (Org.). Modernização e regionalização nos cerrados do CentroNorte do Brasil: Oeste da Bahia, Sul do Maranhão e do Piauí e Leste de Tocantins / Organizadores: Vicente Eudes Lemos Alves. - 1. Ed. - Rio de Janeiro: Consequência Editora, 2015.

ALVES, V. E. L. Mobilização e modernização nos cerrados piavienses: formação territorial no império do agronegócio. FFLCH/USP, tese de doutoramento, 2006.

BRASIL. DECRETO No 8.447, DE 6 DE MAIO DE 2015. Dispõe sobre o Plano de Desenvolvimento Agropecuário do Matopiba e a criação de seu Comitê Gestor. Disponível em: <http://pesquisa.in.gov.br/imprensa/jsp/visualiza/index.jsp?.jornal=1\& pagina $=2 \&$ data $=07 / 05 / 2015>$ Acesso em: 10/06/2015.

BRASIL. Lei 13.005, de 25 de junho de 2014. Aprova o Plano Nacional de Educação - PNE e dá outras providências. Disponível em: <http://http://presrepublica.jusbrasil. com.br/legislacao/125099097/lei-1300514>. Acesso em: 25 de nov. de 2016. 
ELIAS, D. Agronegócio e novas regionalizações no Brasil. Revista Brasileira de Estudos Urbanos e Regionais, v.13, n.2, 2011, pp. 154-167.

FREDERICO, S. As cidades do agronegócio na fronteira agrícola moderna brasileira. Caderno Prudentino de Geografia $[A G B]$, Presidente Prudente, n. 33, v.1, 2011, pp.5-23.

GARAGORRY, F. L.; MIRANDA, E. E. de.; MAGALHÃES, L.A. 2014. MATOPIBA:

Quadro Agrícola. Disponível

em:

<https://www.embrapa.br/gite/publicacoes/NT7_

Matopiba_Quadro_Agricola.pdf.> Acesso em: 20/04/2015.

IBGE. Instituto Brasileiro de Geografia e Estatística. 2014. Disponível em: <http://www.ibge.gov.br/.> Acesso em: 20/03/2014.

INEP. Estatísticas do Ideb 2013 Disponível em: <http://portal.inep.gov.br/web/portal-ideb/planilhas-para-download>. Acesso em: 20 mai. 2015 a.

INEP. InepData Educação Básica. Disponível em: <http://portal.inep.gov.br/inepdata>. Acesso em: 20 mai. 2015b.

LEITE, S. F. Um quadro inicial dos indicadores da formação de professores da educação básica na região do MATOPIBA com base no PNE In: III Congresso Nacional de Formação de Professores (CNFP) e XIII Congresso Estadual Paulista sobre Formação de Educadores (CEPFE), 2016, Águas de Lindóia. São Paulo: UNESP/Prograd, 2016. v.3. p.1 - 12

MIRANDA, E. E. de.; Magalhães, L. A.; Carvalho, C. A. de. Proposta de delimitação territorial do MATOPIBA. Campinas, SP: Embrapa GITE, 2014. Disponível em: <https://www.embrapa.br/gite/publicacoes/NT1_DelimitacaoMatopiba.pdf. > Acesso em: 20/04/2015.

Recebido em: Outubro de 2016 Aceito em: Dezembro de 2016 